\title{
Correlation of Glycated Albumin and Glycated Hemoglobin with Glycemic Control in Patients with Diabetic Chronic Kidney Disease on Hemodialysis
}

Authors:

\begin{abstract}
Zulkhair Ali ${ }^{1}$, Rostika Dewi ${ }^{2}$, Alwi Shahab ${ }^{3}$, Irsan Saleh ${ }^{4}$
1.Division of Nephrology and Hypertension, Department of Internal Medicine, Faculty of Medicine Universitas Sriwijaya - Mohammad Hoesin Hospital, Palembang, South Sumatera, Indonesia

2.Department of Internal Medicine, Faculty of Medicine Universitas Sriwijaya - Mohammad Hoesin Hospital, Palembang .Division of Endocrinology and Diabetes, Department of Internal Medicine, Faculty of Medicine Universitas Sriwijaya - Mohammad Hoesin Hospital, Palembang, South Sumatera, Indonesia
\end{abstract}

4.Department of Pharmacology, Faculty of Medicine, Universitas Sriwijaya, Palembang, South Sumatera, Indonesia

Editor:

Mark Thomas

Received 21 December 2018, revised 8 March 2019, accepted 13 March 2019, published 1 April 2019

\begin{abstract}
Background and aims. Diabetes mellitus (DM) is the most common cause of end-stage renal disease (ESRD) worldwide and is the primary etiology of ESRD in Indonesia. It is estimated that there are 10 million patients with DM in Indonesia and about $25-40 \%$ of diabetics develop diabetic nephropathy (DN) within 25 years. Poor glycemic control is associated with increased mortality in a large observational study among diabetics on hemodialysis. Glycated hemoglobin, or known as $\mathrm{HbAlc}$, was the currently recommended biomarker to monitor long-term glycemic control in diabetes mellitus guideline. However, it becomes underestimated in patients with DN on hemodialysis (DN-HD), because of 20$50 \%$ reduction of erythrocyte lifespan, clinical use of iron therapy, and effects of recombinant human erythropoietin. Glycated albumin (GA), ketoamine formed via a non-enzymatic glycation reaction of serum albumin, is free from interference by erythrocyte lifespan or erythropoietin therapy and subsequently can be used as an alternative biomarker to monitor glycemic control in DN-HD. As albumin has a half-life of only 14-21 days* compared to $\mathrm{Hb} 60-100$ days in well ESKD patients, thus GA may provide a better reflection of recent diabetic control than $\mathrm{HbAlc}$. The aim of this study was to analyze the correlation between GA and HbAlc with glycemic control in DN-HD.
\end{abstract}

Methods The study was an analytical observational study with a cross-sectional design. The subjects were consecutive patients with DN-HD who visited Hemodialysis Unit at Mohammad Hoesin General Hospital Palembang during August-November 2014. The glycemic control index was determined by the average value of 2 times a week pre-HD random blood glucose for 4 weeks (aRBG).

Results. The subjects were 25 patients with an average age of $56.16 \pm 7.49$ years old. The average value of GA was $26.94 \pm 7.74 \%$. GA was strongly correlated with aRBG with $\mathrm{r}=0.776 ; \mathrm{p}=0.000$. After correcting for age, sex, and BMI, the correlations became significantly very strong $(\mathrm{r}=0.809$, $p<0.001)$. The simple linear regression for the relationship between GA and aRBG was $\mathrm{aRBG}=4,62 \times \mathrm{GA}+42.74$ $\left(\mathrm{R}^{2}=0.602, \mathrm{P}<0.001\right)$, estimating that a $1 \%$ increase of GA was associated with $4.62 \mathrm{mg} / \mathrm{dL}$ increase of aRBG. After correcting for age, sex, \& BMI, the correlations between HbA1c and aRBG were significant $(r=0.852, \mathrm{p}<0.001)$.

Conclusion. GA was strongly correlated with glycemic control in patients with DN-HD and HbAlc was correlated better.

Keywords. Glycated albumin, HbA1c, glycemic control, DN-HD.

\section{Corresponding Author:}

Zulkhair Ali. Division of Nephrology and Hypertension, Department of Internal Medicine, Faculty of Medicine Universitas Sriwijaya-Mohammad Hoesin Hospital. Jalan Jenderal Sudirman KM. 3.5, Palembang 30121, email: riset.drzulkhair@gmail.com

\section{INTRODUCTION}

The incidence of diabetes mellitus (DM) is exponentially increased. There are 422 million diabetics worldwide nowadays and it is estimated the number would be 629 million 
diabetics in $2045^{1,2}$. According to the International Diabetes Federation (IDF) data in 2017, Indonesia is ranked sixth of the world's nations for people living with DM. It is estimated that there are 10.3 million diabetics in Indonesia and it is predicted to increase to be 16.7 million in $2045^{2}$. As the consequence for increasing number of diabetics, the incidence of the DM complication, including diabetic nephropathy (DN), becomes a serious public health concern. The previous study estimated that $25-40 \%$ diabetics will develop $\mathrm{DN}$ within 25 years ${ }^{3}$. DN is currently the primary cause for end-stage renal disease (ESRD) worldwide ${ }^{4}$, and is the major etiology for ESRD in Indonesia, according to Indonesian Renal Registry $2015^{5}$.

Previous studies show that poor glycemic control can increase the incidence of cardiovascular complication which becomes the major cause of mortality in patients with $\mathrm{DN}^{6}$. American Diabetes Association (ADA) 2017 recommends two suggested assessments for glycemic control which are self-monitoring blood glucose (SMBG) and hemoglobin $\mathrm{A} 1 \mathrm{c}(\mathrm{HbA} 1 \mathrm{c})^{7}$. HbA1c is widely used as the biomarker for glycemic control and prognostic modality for long-term DM complication because of its nature that reflects average plasma glucose concentration for 2-3 months. In diabetic nephropathy patients undergoing hemodialysis (DN-HD), the measurement of $\mathrm{HbA} 1 \mathrm{c}$ is considered unreliable to quantify long-term glycemic control ${ }^{8}$. The condition is due to the 20-50\% reduction of erythrocyte lifespan, clinical use of iron therapy, effects of recombinant human erythropoietin, uremic conditions, and needs to recurrent blood transfusion in DN-HD ${ }^{9,10}$. Iron therapy and erythropoietin use will be followed by the reduction of HbAlc value without any glycemic status changes.

Glycated albumin (GA) is the ketoamine formed via a non-enzymatic glycation reaction of serum albumin ${ }^{11}$. GA and $\mathrm{HbAlc}$ were both affected by inflammation, but GA is free from interference by erythrocyte lifespan or erythropoietin therapy which was common among patients with hemodialysis. GA has a serum half-life of approximately 20 days compared to HbA1c which has 120 days of serum half-life. The rapid change of GA as the response for glucose concentration changes offers a benefit for diabetics with fluctuated glucose concentration conditions such as postprandial hyperglycemia or abrupt glycemic status changes in short duration ${ }^{11}$. GA is deemed to be used as a better biomarker to monitor glycemic control than $\mathrm{HbA1c}$ in patients with DN-HD who always have anemia. Previous studies show conflicting results. Peacock at $\mathrm{a}^{12}$ and Sany et a ${ }^{13}$ concluded that $\mathrm{HbAlc}$ as the measurement for glycemic control is significantly underestimated compared to GA. The other studies which are done by Ichikawa et $\mathrm{al}^{14}$ and Inaba et al ${ }^{10}$ signified that $\mathrm{HbA} 1 \mathrm{c}$ has stronger correlation compared to GA as glycemic control in DN-HD. The similar studies have been limited and there is no published study about GA and
$\mathrm{HbA1c}$ as glycemic control index in the Indonesian population. The aim of this study was to elaborate on the correlation between GA and glycemic control in patients with DNHD. For the purpose of comparing, this study also aimed to identify the correlation between $\mathrm{HbA} 1 \mathrm{c}$ and glycemic control in patients with DN-HD.

\section{METHOD}

The study was an analytical observational study with a cross-sectional design. The study was conducted in the hemodialysis unit of Mohammad Hoesin General Hospital on August-November 2014. The subjects were consecutively recruited based on the inclusion criteria. All subjects gave their written informed consent. The study was approved by the local Ethics Committee.

The subjects were the patients of DN-HD who were 18-60 years old. They were patients without any history of liver function abnormalities, hemoglobinopathy, and thyroid disease. Pre-HD random blood glucose was measured two times a week for four weeks in an aim to determine average random blood glucose, aRBG, as a measurement of glycemic control ${ }^{15}$. In the last measurement, the GA and HbAlc were also measured. The assessments of GA and HbAlc were conducted in Prodia Laboratory Palembang. Lucica GA-L kit was used to measure GA and ADVIA $1650 \mathrm{au-}$ tomatic instrument was used to analyze the measurement. HPLC-DCCT, a method which becomes a major reference method as used by the National Glycohemoglobin Standardization Program (NGSP), was used to assess HbA1c. $\mathrm{HbA} 1 \mathrm{c}<7 \%$ indicated controlled DM7.

Statistical analysis was performed by SPSS version 22.0 for Windows (SPSS Inc., Chicago, IL, USA). Normally distributed data were expressed as means $\pm \mathrm{SD}$; skewed variables were expressed as medians and minimum-maximum range. Correlations between the GA, HbAlc, GA/HbAlc ratio, and aRBG were evaluated using Pearson correlation coefficient analysis. To examine the influence of confounding variables, multivariate analysis with multiple regression analysis was conducted. Statistical significance was indicated by a two-tailed P-value of $<0.05$.

\section{RESULTS}

The study recruited 25 patients with DN-HD whose characteristic was shown in table 1 . The GA, HbA1c, and aRBG were shown in table 2. GA had a positive strong correlation with aRBG with $\mathrm{r}=0.776 ; \mathrm{p}=0.000$. After correcting for age, sex, and BMI, the correlations became significantly very strong $(\mathrm{r}=0.809, \mathrm{p}<0.001)$. The simple linear regression for the relationship between $\mathrm{GA}$ and $\mathrm{aRBG}$ was $\mathrm{aRBG}=4,62 \times$ $\mathrm{GA}+42.74(\mathrm{Rsq}=0.602, \mathrm{P}<0.001)$. It estimated that a $1 \%$ 
Table 1. The characteristics of subjects

\begin{tabular}{|c|c|}
\hline Characteristics & Value $(n=25)$ \\
\hline \multicolumn{2}{|l|}{ Gender } \\
\hline Male & 11 \\
\hline Female & 14 \\
\hline Age (year) & $56.16 \pm 7.49$ \\
\hline Body mass index $\left(\mathrm{kg} / \mathrm{m}^{2}\right)$ & $21.10 \pm 2.16$ \\
\hline Duration of diabetes (year) & $9.98 \pm 6.35$ \\
\hline Hemoglobin (g/dL) & $7.92 \pm 1.19$ \\
\hline Albumin $(\mathrm{g} / \mathrm{dL})$ & $3.75 \pm 0.48$ \\
\hline
\end{tabular}

Table 2. GA, HbA1c, and aRBG in subjects

\begin{tabular}{cc}
\hline Characteristics & Value (n=25) \\
\hline GA (\%) & $26.94 \pm 7.74$ \\
$\mathrm{HbA} 1 \mathrm{c}(\%)$ & $6.7(5.3-11.4)$ \\
$\mathrm{aRBG}(\mathrm{mg} / \mathrm{dL})$ & $161.25(97.25-308.87)$ \\
\hline
\end{tabular}

increase of GA was associated with $4.62 \mathrm{mg} / \mathrm{dL}$ increase of aRBG.

The correlation between $\mathrm{HbA} 1 \mathrm{c}$ and aRBG was scored noted on $\mathrm{r}=0.869$ and $\mathrm{p}=0.000$. After correcting for age, sex, and BMI, the correlations remained significant $(\mathrm{r}=0.852$, $\mathrm{p}<0.001)$. The relationship between GA and aRBG was $\mathrm{aRBG}=30.96 \times \mathrm{HbA1c}-49.36$ ( $\mathrm{Rsq}=0.754, \mathrm{P}<0.001)$. The analysis estimated that a $1 \%$ increase of $\mathrm{HbA} 1 \mathrm{c}$ was associated with $30.96 \mathrm{mg} / \mathrm{dL}$ increase of aRBG. Meanwhile, the $\mathrm{GA} / \mathrm{HbA} 1 \mathrm{c}$ ratio was weakly correlated and statistically not significant $(\mathrm{Rsq}=0.305, \mathrm{p}=0,139)$.

Table 3 and Table 4 presents the results of a multiple regression analysis of various clinical variables. In table 3 , which included age, gender, body mass index, duration of diabetes in years, and GA, only GA was found significantly correlat-

Table 3. Multivariate regression analysis of glycated albumin and average random blood glucose

\begin{tabular}{lccccc}
\hline \multicolumn{1}{c}{ Clinical Variable } & $\mathrm{B}$ & $\mathrm{SE}(\mathrm{B})$ & $\mathrm{T}$ & Partial Rsq & $P$ \\
\hline Age (years) & 0.340 & 0.708 & 0.048 & 0.011 & $\mathrm{NS}$ \\
\hline Body Mass Index $\left(\mathrm{kg} / \mathrm{m}^{2}\right)$ & -0.511 & 2.696 & -0.190 & -0.042 & $\mathrm{NS}$ \\
\hline Duration of Diabetes (years) & -0.209 & 0.928 & -0.225 & -0.042 & $\mathrm{NS}$ \\
\hline HbA1c (\%) & 31.494 & 4.238 & 7.431 & 0.857 & $<0.001$ \\
\hline Constant & -42.128 & 66.299 & -0.635 & & NS \\
\hline
\end{tabular}

Table 4. Multivariate regression analysis of HbAlc associated with average random blood glucose in patients with diabetic nephropathy undergoing hemodialysis

\begin{tabular}{lccccc}
\hline \multicolumn{1}{c}{ Clinical Variable } & $\mathrm{B}$ & $\mathrm{SE}(\mathrm{B})$ & $\mathrm{T}$ & Partial Rsq & $P$ \\
\hline Age (years) & 0.340 & 0.708 & 0.048 & 0.011 & $\mathrm{NS}$ \\
\hline Body Mass Index $\left(\mathrm{kg} / \mathrm{m}^{2}\right)$ & -0.511 & 2.696 & -0.190 & -0.042 & $\mathrm{NS}$ \\
\hline Duration of Diabetes (years) & -0.209 & 0.928 & -0.225 & -0.042 & $\mathrm{NS}$ \\
\hline HbA1c (\%) & 31.494 & 4.238 & 7.431 & 0.857 & $<0.001$ \\
\hline Constant & -42.128 & 66.299 & -0.635 & & $\mathrm{NS}$ \\
\hline
\end{tabular}

InaKidney | Vol. II | Is. 1| Jan - Apr 2019

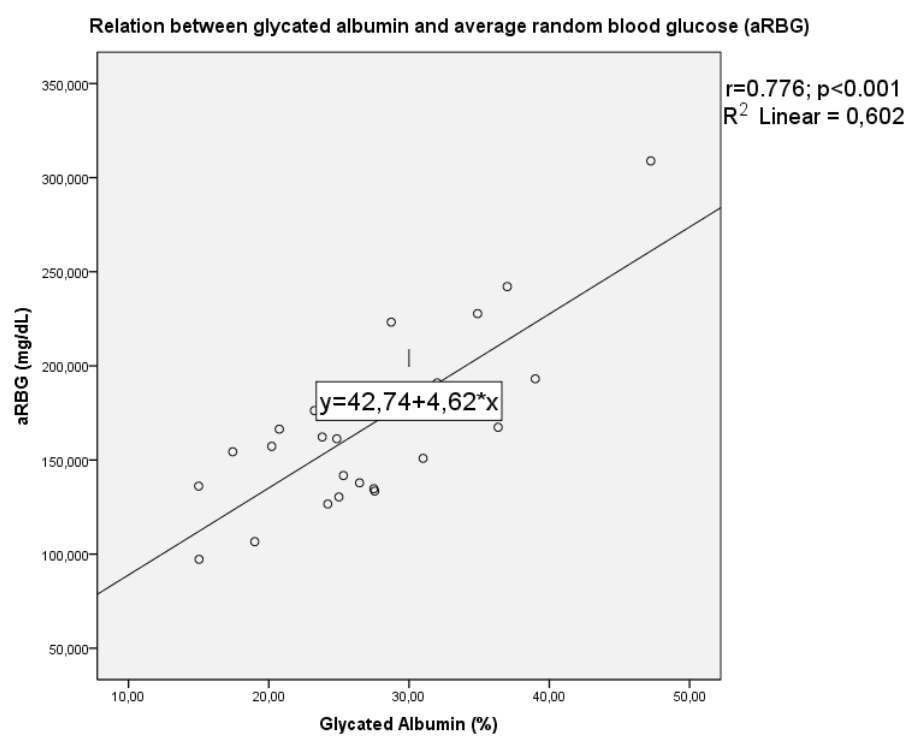

Figure 1. Relation between glycated albumin and average random blood glucose (aRBG). The solid line represents the regression line of all data. Glycated albumin $(r=0.776 ; \mathrm{p}<0.001)$ did have significant positive correlation with aRBG.

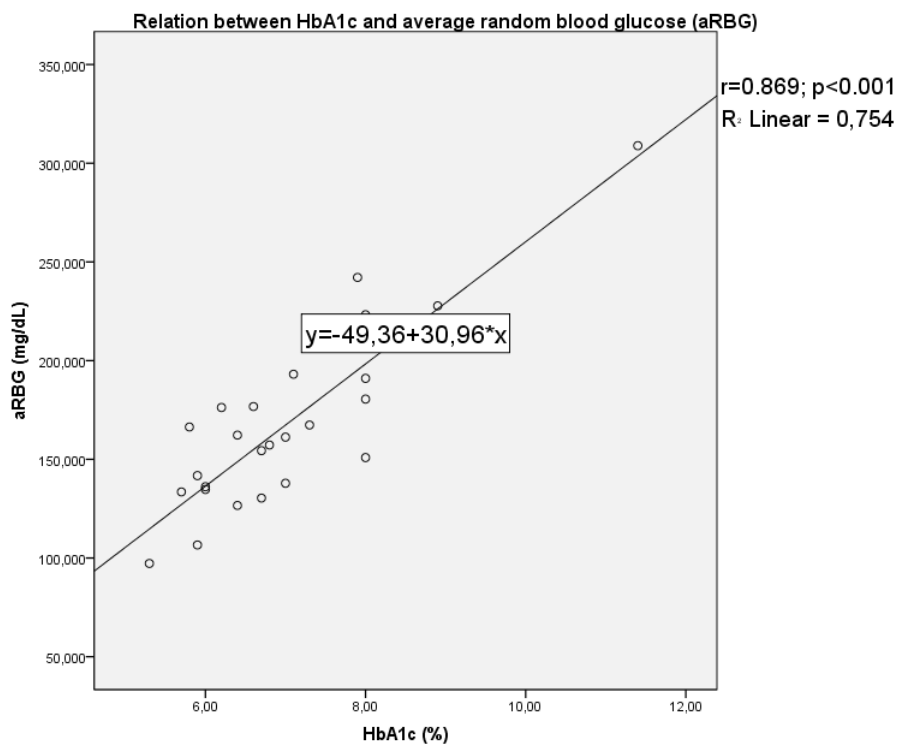

Figure 2. Relation between $\mathrm{HbAlc}$ and average random blood glucose (aRBG). The solid line represents the regression line of all data. HbA1c $(r=0.869 ; \mathrm{p}=<0.001)$ did have significant positive correlation with aRBG.

ed with aRBG. In table 4, which included HbAlc in place of GA, HbA1c emerged as an independent and significant factor that was positively correlated with aRBG.

\section{DISCUSSIONS}

Glycemic control in the study was depicted by aRBG which was the average plasma glucose concentration measured before $\mathrm{HD}, 2$ times a week for 4 weeks duration ( 8 times measurement in total). GA was strongly correlated with aRBG $(\mathrm{p}<0.05 \mathrm{r}=0.776)$. The similar result was also identified by Sany et al who identified a significant positive correlation be- 
tween GA and aRBG $(\mathrm{p}<0.01 \mathrm{r}=0.54)$ and Inaba et al which also showed the significant correlation $(\mathrm{r}=0.52, \mathrm{p}<0.01)^{10,13}$. The correlation between $\mathrm{HbA} 1 \mathrm{c}$ and $\mathrm{aRBG}$ in the study was significant and very strong $(\mathrm{p}<0.05, \mathrm{r}=0.869)$, tending to be stronger compared to Sany et al $(r=0.51, \mathrm{p}<0.01)$ and Inaba et al $(\mathrm{r}=0.52, \mathrm{p}<0.01)^{10,13}$. This study and Inaba et al showed a stronger correlation between $\mathrm{HbA} 1 \mathrm{c}$ and $\mathrm{aRBG}$ compared to GA and aRBG. During hemodialysis, the uremic condition, blood loss due to therapy, and the increased frequency of blood sampling contributed to shortening the erythrocyte lifespan. Thus, in theory, the shortening of erythrocyte lifespan and erythrocyte transfusion made $\mathrm{HbA} 1 \mathrm{c}$ becoming less reliable in the measurement of glycemic control in patients with DN-HD. ${ }^{16}$

$\mathrm{GA} / \mathrm{HbA} 1 \mathrm{c}$ ratio and aRBG in the study showed a weak correlation value and statistically insignificant. The contradictive result was shown by Lee et al which reported that there was a significant association between $\mathrm{GA} / \mathrm{HbA} 1 \mathrm{c}$ ratio and insulin secretion function ${ }^{17}$. Kim et al included standardized liquid meal test for the subject, in comparison to the current study which did not perform the test. The correlation coefficient of GA and aRBG in this study was strong and the correlation coefficient of $\mathrm{HbA1c}$ and aRBG was very strong. This finding was similar to Ichikawa et al who stated that $\mathrm{HbAlc}$ was the gold standard measurement to monitor the glycemic status of patients with $\mathrm{DN}-\mathrm{HD}^{14}$. The dissimilar finding was shown by Freedman et al who reported GA was superior in monitoring glycemic control compared to $\mathrm{HbA1c}$ in patients with DN-HD because GA measured glycemic control for 2-3 weeks duration compared $\mathrm{HbA} 1 \mathrm{c}$ which measured in 1-3 months duration ${ }^{21}$. The conflicting results might be reflected by the factors affecting serum albumin and hemoglobin, such as blood loss and inflammation. Acute and chronic blood loss, besides decreased red cell survival, did lower $\mathrm{HbA} 1 \mathrm{c}$ results in patients with chronic kidney disease ${ }^{22}$. Chronic inflammation, commonly found in patients with DN-HD, affected glycosylation of both GA and HbA1c in intricate fashion ${ }^{23,24}$, thus interfering the result.

Further studies should consider blood loss and inflammation as factors affecting correlation among GA, HbA1c, and glycemic control. Examining the clinical details of the outlier patients, where GA and $\mathrm{HbA} 1 \mathrm{c}$ do not correlate with each other (or with aRBG), may help clarify the risk factors for false-positive and/or false-negative results. With serum halflife of 12-21 days, GA provided information over a period of 1 month compared to 3-6 months with $\mathrm{HbA} 1 \mathrm{c}^{25}$. Future research is warranted to validate our findings in follow-up studies which compared the three months GA value and $\mathrm{HbA1c}$. In the current study, the glycemic control measurement of self-monitoring blood glucose according to ADA recommendation in 2017 , could not be performed due to impracticality. The glycemic control which was determined by 2 times a week measurement for 4 weeks duration could give a bias because of the high variation about nutritional intake and patients' physical stress. The study also did not perform standardized liquid meal in an attempt to minimize the bias which could be produced by blood glucose measurement methods.

\section{CONCLUSIONS}

GA was strongly correlated toward glycemic control in patients with DN-HD, but that HbAlc was correlated even better.

\section{REFERENCE}

1. World Health Organization. Global report on diabetes. World Health Organization; 2016.

2. IDF Diabetes Atlas. (2017). 8th ed. [ebook] IDF. Diunduh dari http://www.diabetesatlas.org/ [Diakses 29 Apr. 2018].

3. Gheith O, Farouk N, Nampoory N, Halim MA, Al-Otaibi T. Diabetic kidney disease: world wide difference of prevalence and risk factors. Journal of nephropharmacology. 2016;5(1):49.

4. Ghaderian SB, Hayati F, Shayanpour S, Mousavi SS. Diabetes and end-stage renal disease; a review article on new concepts. Journal of renal injury prevention. 2015;4(2):28.

5. Perhimpunan Nefrologi Indonesia. 8th Report of Indonesian renal registry. Jakarta: Pernefri. 2011.

6. Zheng Y, Ley SH, Hu FB. Global aetiology and epidemiology of type 2 diabetes mellitus and its complications. Nature Reviews Endocrinology. 2018 Feb;14(2):88.

7. American Diabetes Association. Glycemic targets. Sec. 6. In Standards of Medical Care in Diabetesd2017. Diabetes Care 2017;40(Suppl. 1):S48-S56.

8. Hayashi A, Takano K, Masaki T, Yoshino S, Ogawa A, Shichiri M. Distinct biomarker roles for HbA1c and glycated albumin in patients with type 2 diabetes on hemodialysis. Journal of diabetes and its complications. 2016 Nov 1;30(8):1494-9.

9. Jin YP, Su XF, Yin GP, Xu XH, Lou JZ, Chen JJ, Zhou Y, Lan J, Jiang B, Li Z, Lee KO. Blood glucose fluctuations in hemodialysis patients with end stage diabetic nephropathy. Journal of Diabetes and its Complications. 2015 Apr 1;29(3):395-9. 
10. Inaba M, Okuno S, Kumeda Y, Yamada S, Imanishi Y, Tabata T, Okamura M, Okada S, Yamakawa T, Ishimura E, Nishizawa Y. Glycated albumin is a better glycemic indicator than glycated hemoglobin values in hemodialysis patients with diabetes: effect of anemia and erythropoietin injection. Journal of the American Society of Nephrology. 2007 Mar 1;18(3):896-903.

11. Vos FE, Schollum JB, Walker RJ. Glycated albumin is the preferred marker for assessing glycaemic control in advanced chronic kidney disease. Nephrology Dialysis Transplantation Plus. 2011 Dec 1;4(6):368-75.

12. Peacock TP, Shihabi ZK, Bleyer AJ, Dolbare EL, Byers JR, Knovich MA, Calles-Escandon J, Russell GB, Freedman BI. Comparison of glycated albumin and hemoglobin A1c levels in diabetic subjects on hemodialysis. Kidney international. 2008 May 1;73(9):1062-8.

13. Sany D, Elshahawy Y, Anwar W. Glycated albumin versus glycated hemoglobin as glycemic indicator in hemodialysis patients with diabetes mellitus: variables that influence. Saudi Journal of Kidney Diseases and Transplantation. 2013 Mar 1;24(2):260.

14. Ichikawa H, Nagake Y, Takahashi M, Nakazono H, Kawabata K, Shikata K, Makino H. What is the best index of glycemic control in patients with diabetes mellitus on hemodialysis?. The Japanese Journal of Nephrology. 1996;38(7):305-8.

15. Bilo HJ, Struijk DG, Boeschoten EW, Oe PL, Donker AJ. A comparison of three methods to assess metabolic control in diabetic patients on CAPD treatment. The Netherlands journal of medicine. 1988 Dec;33(56):217-24.

16. Zheng CM, Ma WY, Wu CC, Lu KC. Glycated albumin in diabetic patients with chronic kidney disease. Clinica chimica acta. 2012 Oct 9;413(19-20):1555-61 .

17. Lee YH, Kown MH, Kim KJ, Lee EY, Kim D, Lee BW, Kang ES, Cha BS, Lee HC. Inverse association between glycated albumin and insulin secretory function may explain higher levels of glycated albumin in subjects with longer duration of diabetes. PloS one. 2014 Sep 29;9(9):e108772.

18. Furusyo N, Koga T, Ai M, Otokozawa S, Kohzuma T, Ikezaki H, Schaefer EJ, Hayashi J. Utility of glycated albumin for the diagnosis of diabetes mellitus in a Japanese population study: results from the Kyushu and Okinawa Population Study (KOPS). Diabetologia. 2011 Dec 1;54(12):3028-36.

19. Viswanathan V, Kumpatla S, Tilak P, Muthukumaran P. Levels of glycated albumin at different stages of diabetic nephropathy in India. Int J Diabet Metabol.
2009; 17:77-80.

20. Fukuoka K, Nakao K, Morimoto H, Nakao A, Takatori Y, Arimoto K, Taki M, Wada J, Makino H. Glycated albumin levels predict long-term survival in diabetic patients undergoing haemodialysis. Nephrology. 2008 Jun 1;13(4):278-83.

21. Freedman BI, Shenoy RN, Planer JA, Clay KD, Shihabi ZK, Burkart JM, Cardona CY, Andries L, Peacock TP, Sabio H, Byers JR. Comparison of glycated albumin and hemoglobin A1c concentrations in diabetic subjects on peritoneal and hemodialysis. Perit Dial Int. 2010 Jan 1;30(1):72-9.

22. Nitin $\mathrm{S}$. HbA1c and factors other than diabetes mellitus affecting it. Singap Med J. 2010;51:616-622.

23. Roohk HV, Zaidi AR, Patel D. Glycated albumin (GA) and inflammation: role of GA as a potential marker of inflammation. Inflamm Res. 2018 Jan 1;67(1):21-30.

24. Vlassara H, Uribarri J, Cai W, Goodman S, Pyzik R, Post J, Grosjean F, Woodward M, Striker GE. Effects of sevelamer on HbAlc, inflammation, and advanced glycation end products in diabetic kidney disease. Clin J Am Soc Nephrol. 2012 Mar 29:CJN-12891211.

25. Yazdanpanah S, Rabiee M, Tahriri M, Abdolrahim M, Rajab A, Jazayeri HE, Tayebi L. Evaluation of glycated albumin (GA) and GA/HbA1c ratio for diagnosis of diabetes and glycemic control: a comprehensive review. Critical reviews in clinical laboratory sciences. 2017 May 19;54(4):219-32. 